\title{
GRAMAT: a comprehensive Matlab toolbox for estimating global mass variations from GRACE satellite data
}

\author{
Wei Feng $^{1}$ (D) \\ Received: 20 April 2018 / Accepted: 24 October 2018 / Published online: 20 November 2018 \\ (C) The Author(s) 2018
}

\begin{abstract}
In this paper, we robustly analyze the noise reduction methods for processing spherical harmonic (SH) coefficient data products collected by the Gravity Recovery and Climate Experiment (GRACE) satellite mission and devise a comprehensive GRACE Matlab Toolbox (GRAMAT) to estimate spatio-temporal mass variations over land and oceans. Functions in GRAMAT contain: (1) destriping of SH coefficients to remove "north-to-south" stripes, or geographically correlated high-frequency errors, and Gaussian smoothing, (2) spherical harmonic analysis and synthesis, (3) assessment and reduction of the leakage effect in GRACE-derived mass variations, and (4) harmonic analysis of regional time series of the mass variations and assessment of the uncertainty of the GRACE estimates. As a case study, we analyze the terrestrial water storage (TWS) variations in the Amazon River basin using the functions in GRAMAT. In addition to obvious seasonal TWS variations in the Amazon River basin, significant interannual TWS variations are detected by GRACE using the GRAMAT, which are consistent with precipitation anomalies in the region. We conclude that using GRAMAT and processing the GRACE level-2 data products, the global spatio-temporal mass variations can be efficiently and robustly estimated, which indicates the potential wide range of GRAMAT's applications in hydrology, oceanography, cryosphere, solid Earth and geophysical disciplines to interpret largescale mass redistribution and transport in the Earth system. We postulate that GRAMAT will also be an effective tool for the analysis of data from the upcoming GRACE-Follow-On mission.
\end{abstract}

Keywords GRACE · Satellite gravimetry · Matlab · Destriping · Leakage

\section{Introduction}

Launched in March 2002, the Gravity Recovery and Climate Experiment (GRACE) satellite mission has provided direct observations of the global gravity field and its temporal variations with an unprecedented accuracy (Tapley et al. 2004). As a joint satellite mission between the National Aeronautics and Space Administration (NASA) and the German Aerospace Center (DLR), GRACE has proven to be an invaluable tool for monitoring the mass transport and redistribution in the Earth's fluid envelopes with a footprint of $\sim 300 \mathrm{~km}$. To measure the Earth's gravity field from space, two GRACE

Communicated by: H. A. Babaie

Wei Feng

fengwei@whigg.ac.cn

1 State Key Laboratory of Geodesy and Earth's Dynamics, Institute of Geodesy and Geophysics, Chinese Academy of Sciences, Xudong Road 340, Wuhan 430077, China satellites fly at an altitude of $\sim 450 \mathrm{~km}$ in the same near-polar orbit with one $220 \mathrm{~km}$ ahead of the other. Any mass variation at the Earth's surface, in principle, causes the change of distance between two GRACE satellites, which is detected at micrometer precision. Thus, by observing the distance between two satellites by the K-band ranging (KBR) instrument and orbit perturbations by GPS tracking, GRACE satellites can "sense" the gravity field and its variations in a direct way. The GRACE observations are processed and released by the Center for Space Research (CSR) at the University of Texas at Austin, the Geo-Forschungs-Zentrum (GFZ) at Potsdam, the Jet Propulsion Laboratory (JPL), among others. The main products released by these data processing centers are level-2 GRACE solutions, i.e., geopotential fields in the form of spherical harmonic $(\mathrm{SH})$ coefficients (Stokes coefficients), which can be used to interpret global gravity field changes and mass variations at the Earth's surface.

Numerous studies have demonstrated that GRACE has enabled many achievements in Earth science, e.g., terrestrial water storage (TWS) variations and relevant droughts and 
floods in the Amazon River basin (Chen et al. 2009b, 2010a; Frappart et al. 2012), ice sheet mass balance in Antarctica and Greenland (Harig and Simons 2012; King et al. 2012; Schrama et al. 2014; Velicogna and Wahr 2006a; Velicogna and Wahr 2006b), mass balance in High Mountain Asia (Jacob et al. 2012; Matsuo and Heki 2010; Yi and Sun 2014), groundwater storage depletion (Famiglietti et al. 2011; Feng et al. 2013; Joodaki et al. 2014; Long et al. 2016; Rodell et al. 2009; Scanlon et al. 2012; Tiwari et al. 2009), mass-induced global and regional sea level variations (Boening et al. 2012; Cazenave et al. 2009; Chambers 2006; Feng et al. 2014; García et al. 2006; Kusche et al. 2016; Willis et al. 2008), and coseismic and post-seismic gravity change caused by the 2004 Sumatra-Andaman earthquake (Chen et al. 2007b; Han et al. 2006; Panet et al. 2007). Following the tremendous success of the GRACE mission and its unique contribution to geodesy, hydrology, oceanography and glaciology, the new U.S.-German GRACE Follow-On satellites are scheduled to launch in 2017, with the aim of ensuring the continuity of the GRACE data with a potentially higher accuracy using advanced laser ranging instruments (http://gracefo. jpl.nasa.gov).

However, because of the limited accuracy of the current GRACE payload and the orbit configuration of GRACE satellites, the signal-to-noise ratio of original GRACE level-2 products is relatively low. In addition, there are highly correlated errors in the gravity field coefficients, which result in north-south stripes in the spatial domain. The post-processing procedure to remove the correlated errors is called destriping. Swenson and Wahr (2006) first proposed a destriping method to reduce the correlation among the gravity field coefficients based on polynomial fitting. Thereafter, more destriping methods were proposed to interpret regional and global mass variations in various case studies (e.g., Chambers 2006; Chen et al. 2007b; Duan et al. 2009). After the destriping process, generally, a Gaussian filter is applied to further reduce high-degree noise in GRACE products (Jekeli 1981; Wahr et al. 1998). In addition to this two-step post-processing method (i.e., destriping+Gaussian filter), additional filters were devised to reduce the noise of GRACE solutions, e.g., the non-isotropic filter (Han et al. 2005), the statistical filter (Davis et al. 2008), the DDK filter (Kusche 2007), the wavelet filter (Schmidt et al. 2006), the wiener filter (Sasgen et al. 2007), and the fan filter (Zhang et al. 2009). However, the classic "destriping+Gaussian filter" method remains one of the most widely used methods for processing GRACE level2 products.

As mentioned above, noise reduction should be applied before further interpretation of GRACE level-2 products. To facilitate the application of GRACE data, post-processed gridded level-3 products are also available on the official GRACE Tellus website (https://grace.jpl.nasa.gov/). In addition, there are on-line visualization and analysis tools on the market, e.g., the GRACE Plotter (http://www. thegraceplotter.com/) from the Centre National d'Etudes Spatiales (CNES, France), the visualization tool from GFZ (http://icgem.gfz-potsdam.de/ICGEM/ICGEM.html), and the GRACE data analysis website from the University of Colorado Boulder, USA (http://geoid.colorado.edu/grace/ dataportal.html). However, for these gridded level-3 products and on-line tools, only the results with specific destriping methods and Gaussian filters are available. Therefore, users cannot assess the differences between various methods and select an optimal one for their case study. In addition, these gridded products cannot provide an unbiased time series of mass variations in a user-specified region, because the signal leakage effect in the region is variant on a case-by-case basis. Moreover, the uncertainties in GRACE products cannot be assessed and provided in most available analysis tools. To alleviate these inconveniences and provide more flexibility, an open-source GRACE Matlab Toolbox (GRAMAT) was developed in this study. Based on the GRAMAT, spatiotemporal mass variations can be estimated from GRACE level-2 data with user-friendly graphical user interfaces (GUIs). Users can also implement the leakage reduction process, assess the uncertainty of GRACE mass estimates, and tentatively modify source codes in GRAMAT to develop their own post-processing methods.

\section{Design and implementation}

\section{Workflow of the GRAMAT}

Figure 1 illustrates the workflow of the GRAMAT program. It contains two primary stages: the processing of original GRACE level-2 data to retrieve global or regional mass variations in the spatial and temporal domains, and the processing of hydrological model data to reduce the bias and leakage of the GRACE results.

The first step is processing the GRACE level-2 GSM data, which represent the mass variation signals on the land, as mass variations in the atmosphere and ocean are removed during the gravity inversion process. For oceanographic applications, atmosphere and ocean de-aliasing products (GRACE GAD products) must be added back to represent the mass variations in oceans. In addition, Matlab GUIs are presented to facilitate the use of functions in GRAMAT. For example, Fig. 2 shows the Matlab GUI to process GRACE GSM products. In this GUI, the users can select GSM products from different data processing centers, select the destriping methods, replace lowdegree coefficients, eliminate the glacial isostatic adjustment (GIA) effect, select the output format of results, among other 
Fig. 1 Schematic workflow of the GRAMAT program. Bold abbreviations represent the formats of the data or output, i.e., in the spectral (SHC: spherical harmonic coefficients), spatial (Grids) or temporal (TS: time series) domains

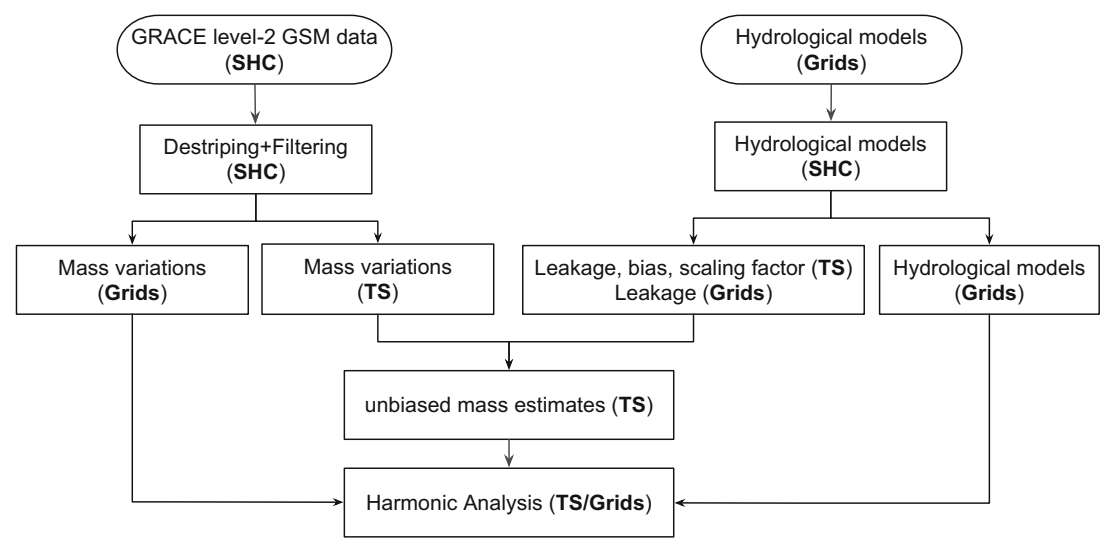

\section{GRAMAT functions}

poral domains can be retrieved. As shown in Fig. 1, in addition to the processing of GRACE original level-2 data, bias and leakage during the GRACE data processing can be further estimated. In GRAMAT, hydrological models can be used to estimate the signal leakage and attenuation due to destriping and smoothing. The rescaling process can be accomplished to recover actual mass variations. In addition, the harmonic analysis of mass variation time series can be performed. Additionally, the uncertainty of the mass variation estimates can be estimated based on the functions in GRAMAT.
The main Matlab functions in GRAMAT and their descriptions are summarized in Table 1. A detailed description of main functions is given as follows:

(1) gmt_readgsm: This function can be used to read the GRACE level-2 GSM files. There are two formats of GSM files, both of which can be read by the function. One is the official GRACE format; the other one is defined by the International Centre for Global Earth

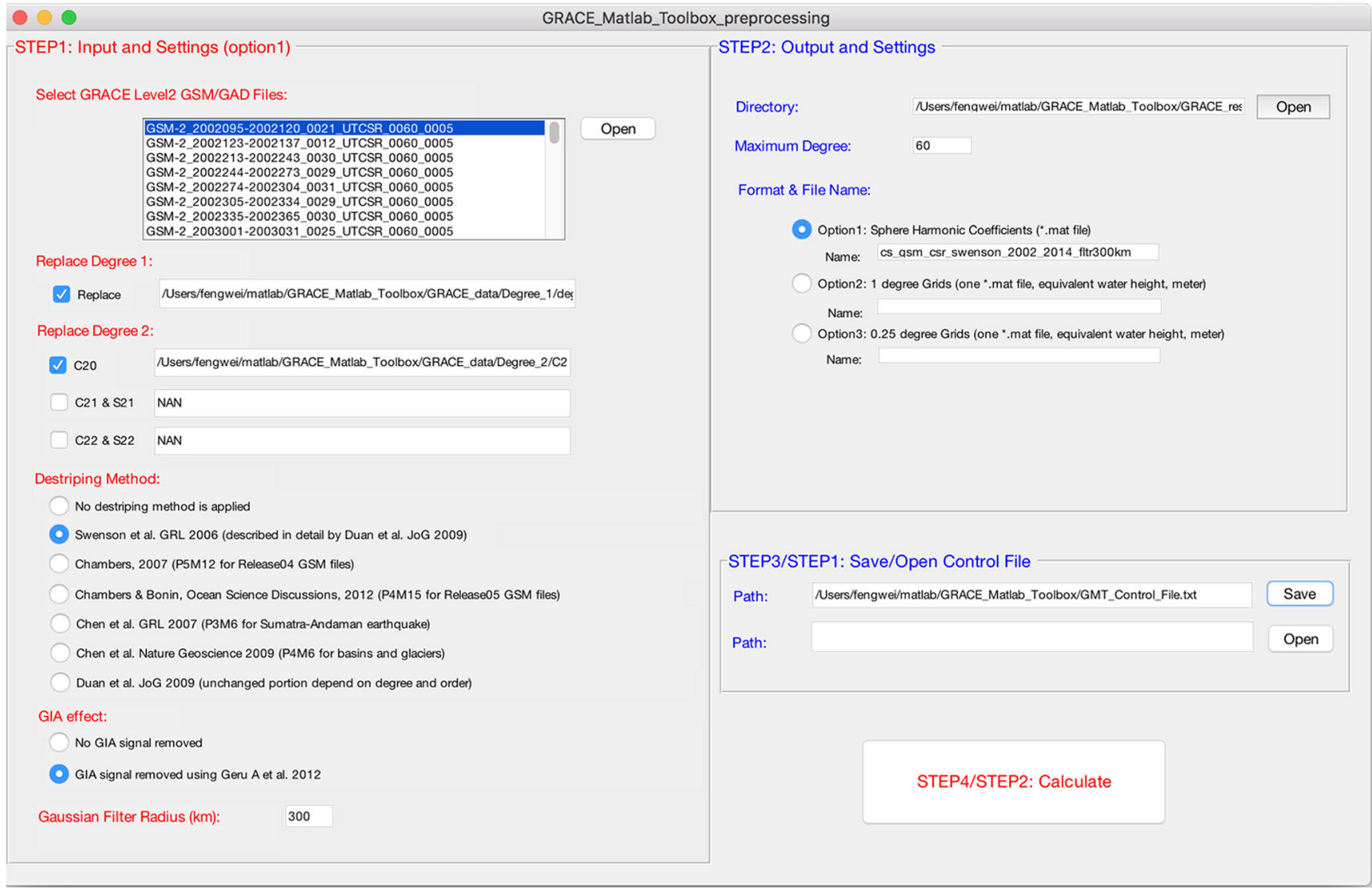

Fig. 2 A Matlab GUI in GRAMAT to process GRACE level-2 GSM data 
Table 1 Main Matlab functions in GRAMAT and their description

\begin{tabular}{ll}
\hline Names & Function descriptions \\
\hline gmt_readgsm & Read the GRACE level-2 GSM data \\
gmt_replace_degree_1 & $\begin{array}{l}\text { Replace the degree-1 coefficients } \\
\text { Replace the C20 coefficients }\end{array}$ \\
gmt_replace_C20 & Implement the destriping of SH coefficients \\
gmt_destriping & Implement the Gaussian smoothing of SH coefficients \\
gmt_gaussian_filter & Convert SH coefficients of geoid to SH coefficients of mass \\
gmt_gc2mc & Convert SH coefficients of geoid to SH coefficients of loading deformation \\
gmt_gc2lc & Spherical harmonic synthesis: calculate global gridded values from SH coefficients \\
gmt_cs2grid & Spherical harmonic analysis: calculate SH coefficients from global gridded values \\
gmt_grid2cs & Estimate the error of original and post-processed GRACE SH coefficients \\
gmt_cs_error & Visualize the global distribution of gridded data \\
gmt_grid2map & Calculate regional average values from global gridded data \\
gmt_grid2series & Perform harmonic analysis of time series \\
gmt_harmonic &
\end{tabular}

More details on all functions in GRAMAT are available from a public Git repository: https://github.com/ fengweiigg/GRACE_Matlab_Toolbox
Models (ICGEM), i.e., ICGEM format. Both of them contains the same GRACE GSM data but in different formats.

(2) gmt_replace_degree_1: As the reference frame origin used by GRACE is the Earth's center of mass, the degree one Stokes coefficients are zero in this frame. However, changes in the degree one terms need to be considered, when we interpret mass variations in the centre-of-figure frame. In this function, degree- 1 terms estimated by Swenson et al. (2008) are used to substitute original GRACE degree one terms.

(3) gmt replace C20: Because the original C20 (degree 2 order 0) coefficients have large uncertainties, the independent estimates from the Satellite Laser Ranging (SLR) are used to replace the original ones from GRACE solutions. In this function, the SLR-based C20 values from Cheng et al. (2013) are used.

(4) gmt destriping: This function provides several destriping methods to reduce correlated errors in GRACE SH coefficients. The details on destriping methods will be discussed later.

(5) gmt_gaussian_filter: In this function, a Gaussian filter with user-defined radius can be applied to SH coefficients to suppress high-frequency noises in $\mathrm{SH}$ coefficients.

(6) gmt gc2mc: This function can be used to convert SH coefficients of geoid from GRACE GSM products into $\mathrm{SH}$ coefficients of mass changes in equivalent water height.

(7) gmt_gc2lc: This function can be used to convert SH coefficients of geoid from GRACE GSM products into SH coefficients of loading deformation.

(8) gmt_cs2grid: In this function, SH coefficients in the spectral domain can be converted into gridded values in the spatial domain with a specified resolution, i.e., 0.25 degree, 0.5 degree, or 1 degree.

(9) gmt grid2cs: In this function, global gridded values can be transformed into SH coefficients with a specified maximum degree.

(10) gmt_cs_error: This function can be used to calculate GRACE measurement errors in SH coefficients based on the method proposed by Wahr et al. (2006).

(11) gmt grid2map: This function visualizes the global spatial pattern of gridded values based on the $m$ map mapping tools.

(12) gmt grid2series: This function can be used to retrieve time series of mass changes in a specific region from grids. In addition to gridded values, the boundary file should be given as input data, which includes the total number of boundary points and their latitudes and longitudes.

(13) gmt harmonic: This function can be used to perform harmonic analysis of time series. The annual, semiannual cycles and the trend can be estimated based on the least square fitting in this function. After removing these estimated components, interannual variations of time series can be derived.

\section{GRAMAT implementation}

As a core part of GRAMAT, the GRACE level-2 GSM data processing can be executed by running the Matlab script file GRACE_Matlab_Toolbox_preprocessing_core.m with a control file as input and processed grid values or SH coefficients as output. In addition to creating a control file by users themselves, the Matlab GUI was developed to facilitate the use of 
functions on the GSM data processing as shown in Fig. 2. The GUI will also create the input control file for the script Matlab_Toolbox_preprocessing_core.m. The format of the control file was pre-defined and explained as follows.

As exemplified in Fig. 3, the first line of the control file contains the total number of GSM files. The second line represents the radius of Gaussian filtering. If " 0 " is given in this line, no Gaussian filtering will be applied to SH coefficients. The third line specifies the destriping method used, with the options of NONE, SWENSON, CHAMBERS2007, CHAMBERS2012, CHENP3M4, CHENP4M6, and DUAN. The explanation of these destriping methods will be given later. The forth line specifies whether the GIA effect will be removed or not with two predefined options, i.e., GIA notRemoved and GIA_Removed_Geru. The fifth line specifies the format of GRACE data with two options, i.e., ICGEM and GRACE. The sixth line specifies the format and name of output data. The first parameter in this line represents the format of output data, which is in the form of SH coefficients (SH_MAT) or of gridded values (GRID_MAT) saved as Matlab MAT-files. The second parameter in the line represents the maximum degree of SH coefficients will be saved as output or used for creating gridded values, which should be less than the maximum degree of input GSM data. The third parameter specifies the name of output file. If the first parameter in this line is "GRID_MAT", there will be the fourth parameter to define the spatial resolution of gridded values with options of $0.25,0.5$, and 1 . The seventh line specifies the full pathname of the C20 file. If "NAN" is given in this line, original C20 values will not be replaced by the SLR-based ones. The eighth and ninth lines are set to be "NAN" generally, but can also be used to replace other degree- $2 \mathrm{SH}$ coefficients by the SLR-based ones with full pathnames. The tenth line specifies the full pathname of the degree- 1 file. The eleventh and twelfth lines specify the directories of input GSM files and the output file, respectively. From the thirteenth line to the end of the control file give the names of input GSM files.

The output gridded data after running the script file GRACE_Matlab_Toolbox_preprocessing_core.m can be further used to retrieve time series of mass changes in a given region using the function gmt_grid2series and to illustrate the spatial pattern of mass changes globally using the function gmt_grid2map. Then, the function gmt_harmonic can be used to do the harmonic analysis of time series. The bias and leakage during the GRACE data processing can be estimated by using the functions gmt_grid 2 cs and gmt_cs2grid. The uncertainty of the mass variation estimates due to GRACE measurement errors can be estimated based on the function gmt_cs_error.

\section{Destriping methods in the function gmt_destriping}

As a core function in GRAMAT, gmt_destriping can be used to reduce correlated errors in the GRACE GSM data. The main destriping (i.e., decorrelation) methods used in the function are explained as follows. In the spatial domain, the original unconstrained monthly gravity field observed by GRACE shows north-south stripes, which represent the correlated errors in the gravity field coefficients. As an example, Fig. 4a illustrates the spatial pattern of mass variations in November 2003 from the original GRACE Stokes coefficients. Swenson and Wahr (2006) found that for a given order $m$, Stokes coefficients of the same parity are correlated with each other. They proposed a method to reduce the correlation by using a quadratic polynomial in a moving window of width $w$ centered at degree $l$. For example, for $C_{l, m}$, they used the Stokes coefficients $C_{l-2 \alpha, m}, \ldots, C_{l-2, m}, C_{l, m}, C_{l+2, m}, \ldots, C_{l+2 \alpha, m}$ to fit a
Fig. 3 A sample of the control file used in GRAMAT

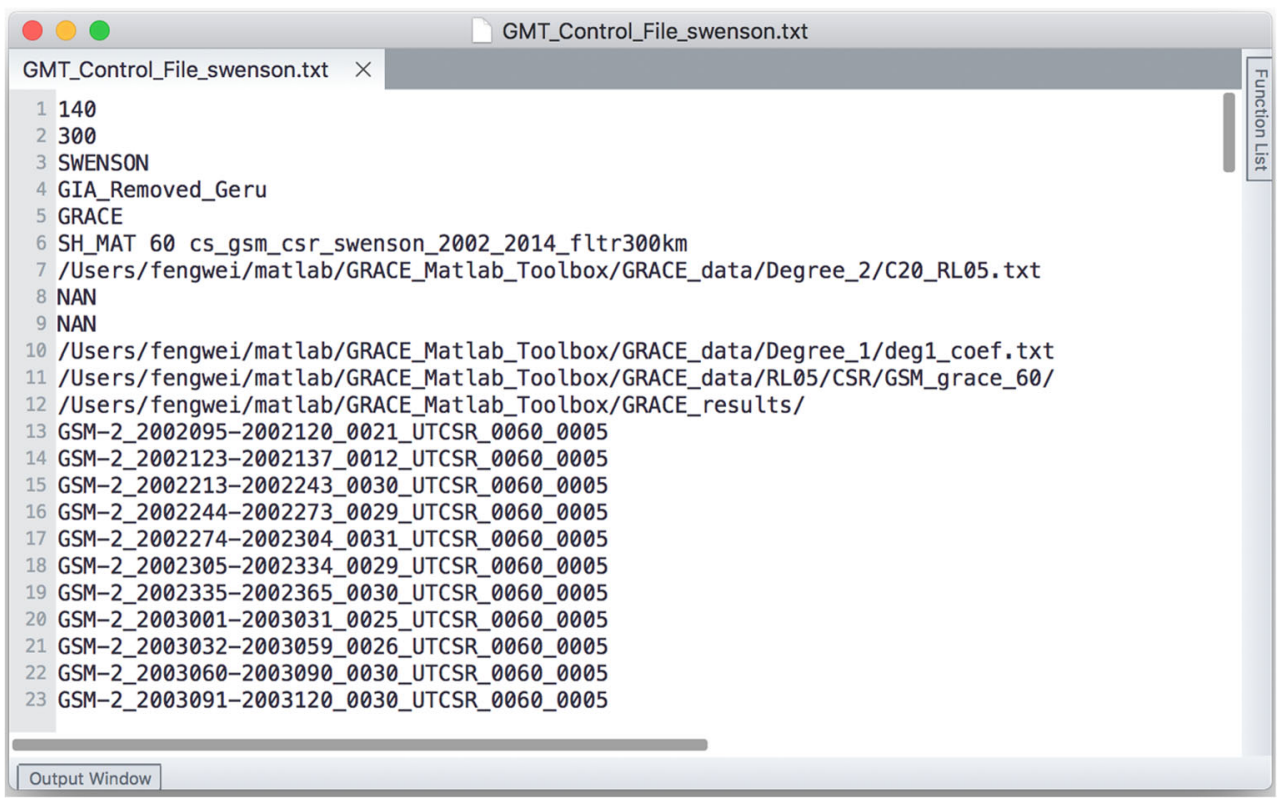


Fig. 4 a Spatial pattern of mass variations in November 2003 obtained from GRACE Stokes coefficients, with no destriping and Gaussian smoothing applied. b Identical to (a), but a $300 \mathrm{~km}$ Gaussian smoothing was applied. (c-f) Identical to (b), but destriping methods developed by Swenson and Wahr (2006), Chambers and Bonin (2012), Chen et al. (2007b), and Duan et al. (2009) were applied
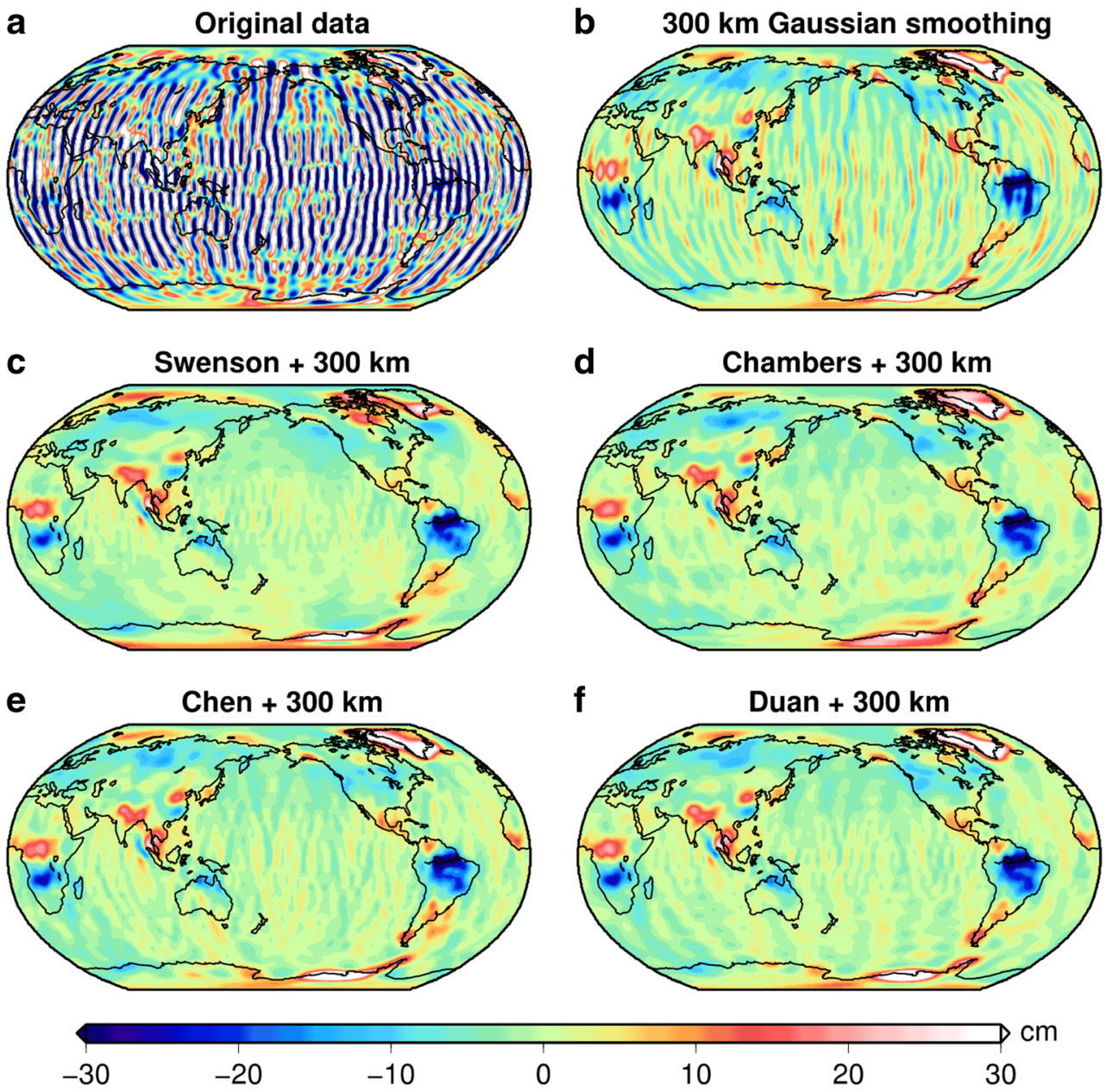

quadratic polynomial, and removed the fitted value from the original $C_{l, m}$ to derive the de-correlated $C_{l, m}$. The relation between the width $w$ of the moving window (i.e., the number of coefficients used for the quadratic polynomial fitting) and $\alpha$ is $w=2 \alpha+1$. However, an algorithm to determine the width of moving window was not provided in the paper. Referring to the unpublished results of Swenson and Wahr (2006), Duan et al. (2009) provided the window width in the form of.

$w=\max \left(A e^{-\frac{m}{K}}+1,5\right)$

where $m$ is the order $(\geq 5)$; $\max ()$ takes the larger of two arguments. Swenson and Wahr (2006) empirically selected $A=30$ and $K=10$ based on a trial-and-error procedure.

To estimate ocean mass change using GRACE, Chambers (2006) modified the algorithm shown above. For the RL02 GRACE solutions, they kept the coefficients of degrees no more than 7 unchanged and fit a 7th-order polynomial to the remaining coefficients of degrees with the same parity for each order up to 50 . In their method, only one polynomial is used for the odd/even set of a given order, unlike in the method developed by Swenson and Wahr (2006). For the RL04 GRACE solutions, Chambers (2006) kept the coefficients no more than 11 unchanged, and a 5th-order polynomial was applied. For the latest RL05 GRACE solutions, the optimal parameterization for ocean mass variation estimation based on the model test is to start filtering at degree 15 , and use a 4thorder polynomial (Chambers and Bonin 2012). This processing method is designated as P4M15. In addition, Chen et al. (2007b) used the P3M6 method to process GRACE data and estimated the coseismic and post-seismic gravity changes caused by the Sumatra-Andaman earthquake. Later, they used the P4M6 method to estimate the mass balance of ice caps, mountain glaciers, and terrestrial water storage change (Chen et al. 2007a, 2008, 2009a, b, 2010a, b). By contrast, Duan et al. (2009) determined the unchanged portion of coefficients based on the error pattern of the coefficients. Their unchanged portion of coefficients and the width of the moving window depend on both degree and order in a more complex manner.

In summary, the parameterization of destriping methods for GRACE depends on the following criteria:

(i) Determination of the unchanged portion of the coefficients: Swenson and Wahr (2006), Chambers (2006) and Chen et al. (2007b), respectively, kept the first 4, 14 
and 5 degrees and orders unchanged, whereas Duan et al. (2009) determined the unchanged portion of the coefficients based on their error pattern, which depends on both degree and order.

(ii) Selection of the degree of polynomial fitting: Swenson and Wahr (2006) and Duan et al. (2009) used a quadratic polynomial, whereas Chambers (2006) and Chen et al. (2007b) used a 7th- and a 3rd-order polynomial, respectively.

(iii) Application of the polynomial fitting to the coefficients (moving window vs. fixed window): Swenson and Wahr (2006) used a moving window with the width depending on the degree, whereas Duan et al. (2009) determined the width of the moving window as a function of both degree and order. Chambers (2006) and Chen et al. (2007b) used a fixed window to fit the polynomial.

In the function gmt_destriping, the aforementioned methods can be applied by using the options of SWENSON, CHAMBERS2007, CHAMBERS2012, CHENP3M4, CHENP4M6, and DUAN. For example, Fig. 4(b-f) shows the global mass variations in November 2003 obtained from GRACE Stokes coefficients based on different destriping methods using gmt_destriping. As shown in Fig. 3(c-f), there is a general consistency among the results from different destriping methods, in which the north-south stripes are significantly reduced. In addition, the destriping process suppresses the north-south stripes more efficiently, compared with only the Gaussian smoothing.

In addition to global mass variations in the spatial domain, the corresponding Stokes coefficient values in the spectral domain are further illustrated in Fig. 5. The mean values of Stokes coefficients over 2002-2014 were removed. Thus, these residual coefficients represent the mass variations. The high variability of high-degree Stokes coefficients mainly represents noise in the original GRACE products (Fig. 5a). As shown in Fig. 5(be), further destriping process mentioned above significantly reduces noise in high-degree coefficients but retains the signals in low-degree coefficients.

For example, we show the GRACE Stokes coefficients $\left(\mathrm{C}_{\mathrm{nm}}\right)$ of the 25th order in November 2003. In Fig. 6a, Stokes coefficients of even or odd parity of the degrees for the same order show high correlations. These apparent correlations represent systematic errors in high-order coefficients (Swenson and Wahr 2006). In fact, Fig. 6a demonstrates these high correlations in even- or odd-degrees for a fixed order. With the destriping methods discussed above, these systematic errors are significantly reduced (e.g., Fig. 6b), and the results in the spatial domain are dramatically improved (Fig. $4(\mathrm{c}-\mathrm{f})$ ).
Leakage and bias in GRACE level-2 data processing

GRACE solutions are expressed as the Stokes coefficients with a limited maximum degree $l_{\max }$. Therefore, the spatial resolution of GRACE products is limited to $\sim 2,000 / l_{\max } \mathrm{km}$ in terms of half-wavelengths. Truncation of SH solutions in the spectral domain is equivalent to a low-pass filtering in the spatial domain. The actual mass variation signal in a given region may be dampened because of the limited SH expansion. In addition, the post-processing procedure (e.g., destriping and Gaussian smoothing) may make the average estimate in a given region biased. The signal in the target region may leak to the surrounding areas and cause amplitude damping in the region (leakage-out), and the signal from the surrounding areas may also leak into the target region (leakage-in).

As an example, the leakage-in and leakage-out effects are demonstrated in the spatial domain in the Amazon River basin using the simulated TWS variations based on the Global Land Data Assimilation System (GLDAS) model from the National Aeronautics and Space Administration (NASA) (Ek et al. 2003; Rodell et al. 2004). Fig. 7a shows the simulated TWS variations in March 2003 in the Amazon River basin and its surrounding regions from the GLDAS Noah model. The spatial resolution and signal magnitude decrease when the grid is transformed into SH coefficients and up to the degree/order (d/o) of 60 using the function gmt_grid2cs (Fig. 7b). To estimate the leakage-out effect in the spatial domain, we maintained the simulated TWS variations in the Amazon River basin from the model and set the values outside the basin to zero. Then, based on the gmt_grid2cs and gmt_cs2grid functions in GRAMAT, we performed the SH analysis and synthesis to obtain the leakage-out effect due to the finite SH expansion. As shown in Fig. 7c, the signal inside the basin leaked into the surrounding regions (leakage-out). Furthermore, we kept the grid values outside the basin but set the values in the basin to zero and performed the $\mathrm{SH}$ analysis and synthesis to recalculate the grid values in the basin. As illustrated in Fig. $7 \mathrm{~d}$, the leakage-in effects are more significant in the marginal regions of the basin than in its center because they are closer to the signals outside the basin. In addition to the leakage effect due to SH truncation shown in Fig. 7, leakage effects can be caused by the destriping and smoothing process. The leakage effects during GRACE data processing can also be estimated in GRAMAT. It should be noted that most model-simulated TWS variations generally do not include groundwater and surface water and have large uncertainties especially for long-term trends, which will induce errors in leakage estimation. However, hydrological models provide independent TWS estimates which can be used to calculate the leakage effects during GRACE data processing.

Wahr et al. (1998) and Swenson and Wahr (2002) considered "leakage" to include both signal leaking out of the target 
a

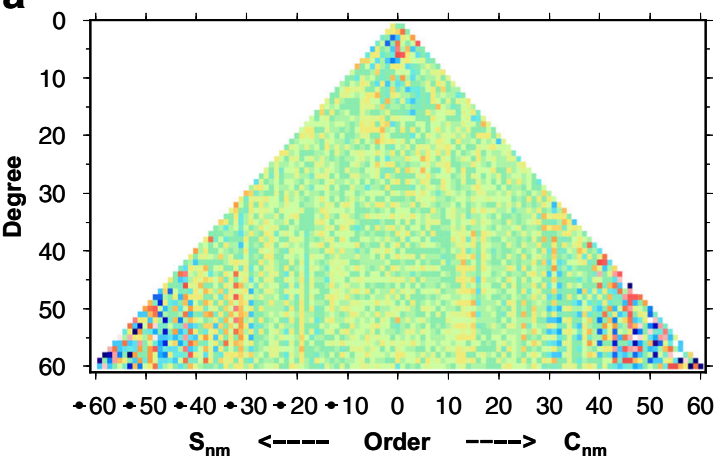

C

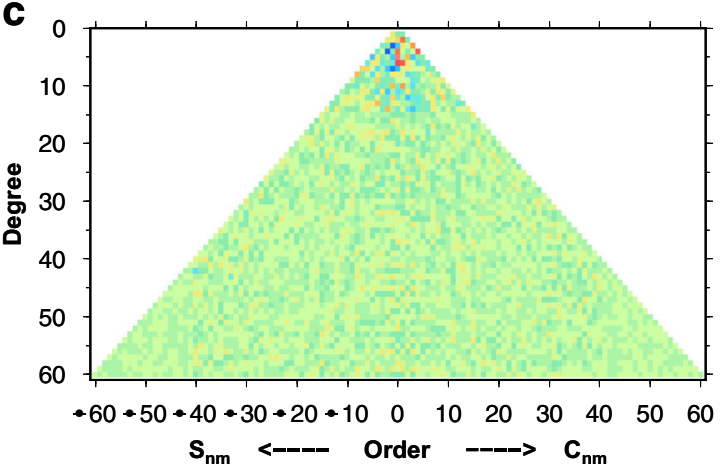

e

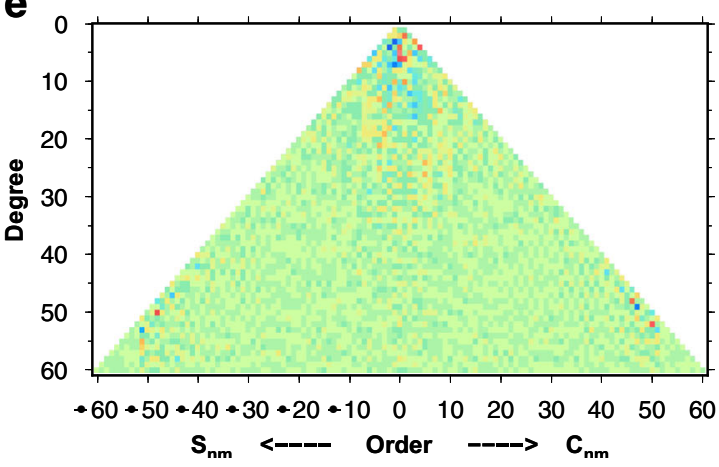

Fig. 5 a Stokes coefficients, converted to mass using Love numbers, from the GRACE products in November 2003. The mean values of Stokes coefficients over 2002-2014 have been removed. b-e Destriped

region and signal leaking into the target region from the surrounding areas. However, Klees et al. (2007) and Longuevergne et al. (2010) called the leakage-out effect "bias" and the leakage-in effect "leakage". In their naming convention, "leakage" only represents the contamination from outside of the target region. In this paper, if not specifically mentioned, we use the latter name convention.

Suppose function $S$ describes the actual mass variations on the Earth's surface, then the mean value of mass variations over the region of interest $R$ is.

$\bar{S}_{0}=\frac{1}{R_{0}} \int_{\Omega} S h d \Omega$

where $R_{0}$ is the area of the region, $h$ is the ideal basin function b

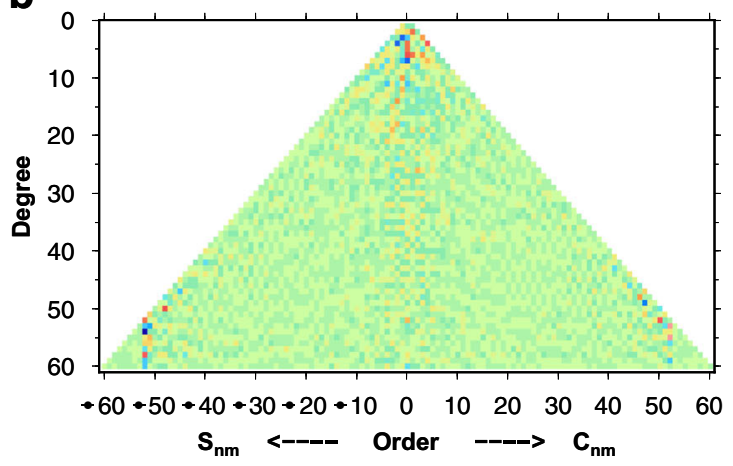

d
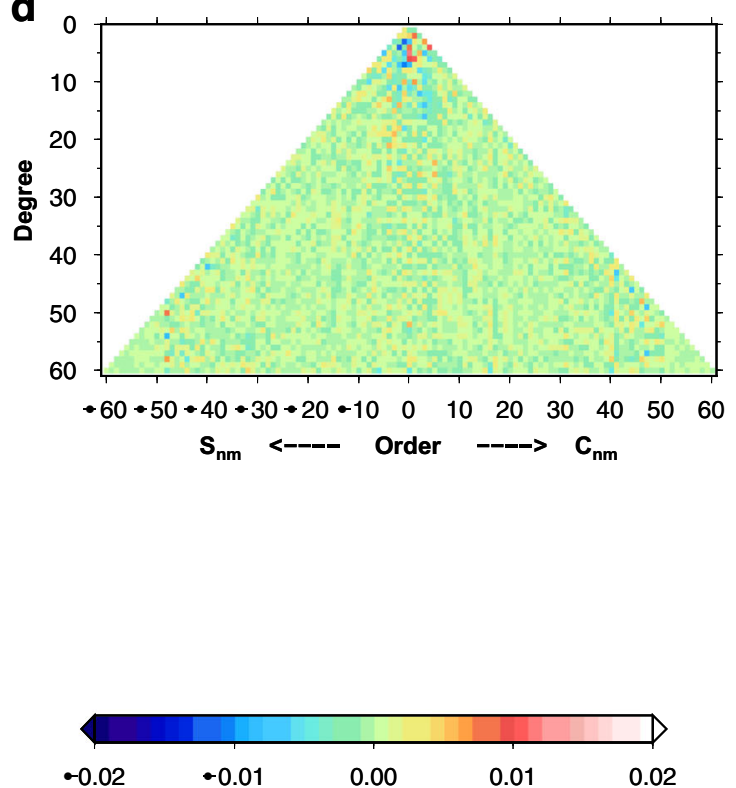

Stokes coefficients based on the methods developed by Swenson and Wahr (2006), Chambers and Bonin (2012), Chen et al. (2007b), and Duan et al. (2009)

( 1 inside the basin; 0 outside), and $\Omega$ represents the entire Earth surface.

The GRACE estimate of the mean value over the region of interest $R$ is.

$\hat{\overline{S_{0}}}=\frac{1}{R_{0}} \int_{\Omega} \hat{\bar{S}} h d \Omega$

where $\hat{\bar{S}}$ is the filtered GRACE estimate of mass variation.

To recover the actual average mass variation signal $\bar{S}_{0}$ in a given region from the GRACE estimate $\hat{\bar{S}}_{0}$, there are two methods. In the first method, the actual average mass variation signal $\bar{S}_{0}$ in a given region is re-written as shown in Eq. (4) (Klees et al. 2007). 
Fig. 6 a Stokes coefficients $\left(\mathrm{C}_{\mathrm{nm}}\right)$, converted to mass using Love numbers, plotted as a function of degree $n$ for order $m=$ 25 from GRACE products in November 2003. The mean values of Stokes coefficients over 2002-2014 have been removed. The dashed red line and blue line show the Stokes coefficients of even and odd degrees, respectively. b Destriped Stokes coefficients $\left(\mathrm{C}_{\mathrm{nm}}\right)$ based on the methods developed by Swenson and Wahr (2006), Chambers and Bonin (2012), Chen et al. (2007b), and Duan et al. (2009) a

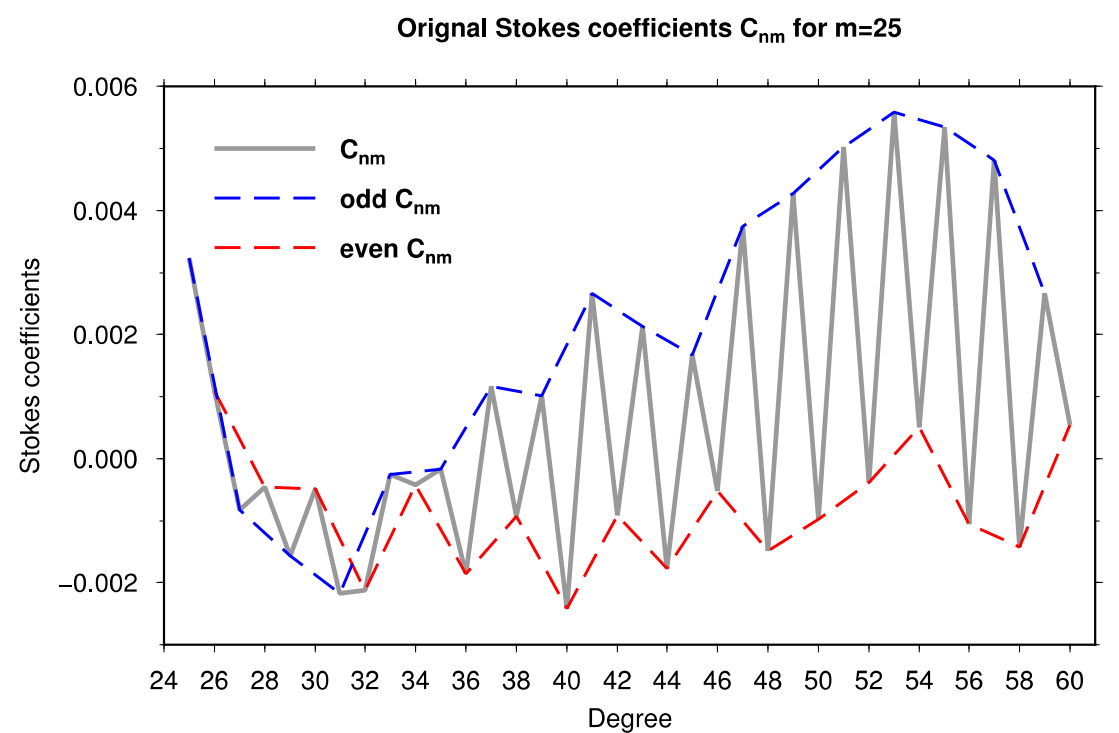

b Destriped Stokes coefficients $C_{n m}$ for $m=25$

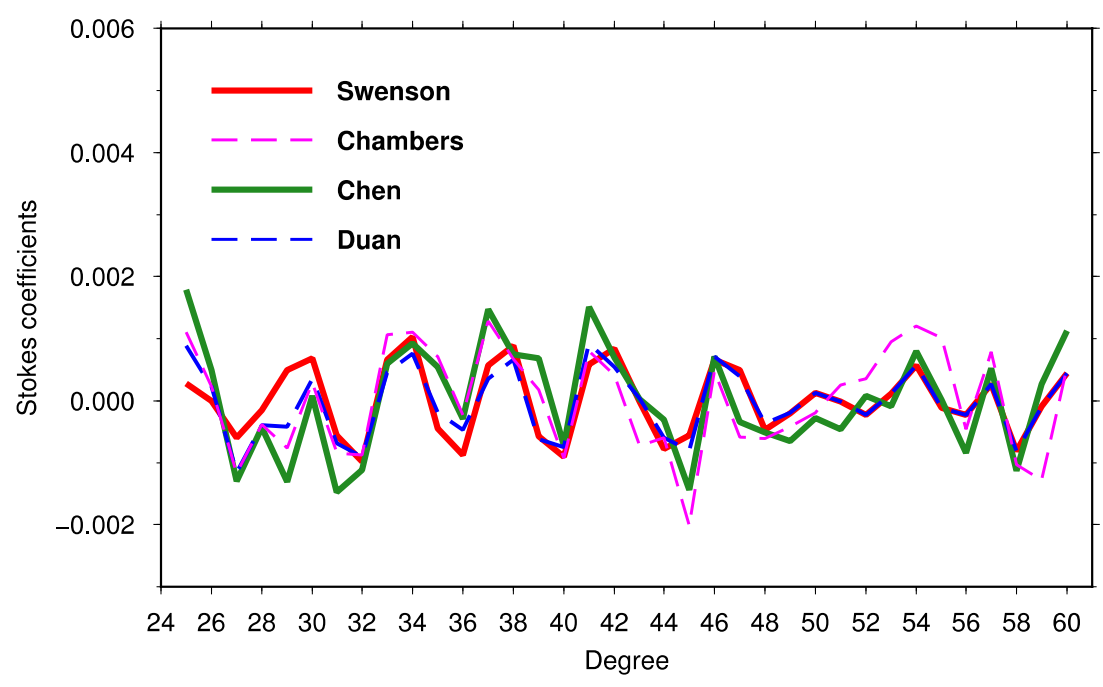

$\bar{S}_{0}=\hat{S_{0}}-S_{\text {leakage }}+S_{\text {bias }}$

with.

$S_{\text {leakage }}=\frac{1}{R_{0}} \int_{\Omega-\mathrm{R}} S_{\text {out }} \hat{h} d \Omega$

$S_{\text {bias }}=\frac{1}{R_{0}} \int_{\mathrm{R}} S_{\text {in }}(h-\hat{h}) d \Omega$

where $S_{\text {in }}$ and $S_{\text {out }}$ are the actual mass variations in the region of interest and outside it, respectively, and $\hat{h}$ is the averaging kernel applied to the GRACE data.

In this method, we must first remove the leakage $S_{\text {leakage }}$ from the GRACE estimate $\hat{\bar{S}}_{0}$ and then add the bias $S_{\text {bias }}$ back. To calculate the leakage and bias for a region, a priori information about mass variations both inside and outside the region of interest should be available, which commonly comes from hydrological models and ocean models. Note that the uncertainty of a priori information may cause the overestimation or underestimation of the leakage and bias.

For the other method, we provide the following equation:

$\bar{S}_{0}=k\left(\hat{S_{0}^{\hat{n}}}-S_{\text {leakage }}\right)$

where $k$ is the scaling factor (or multiplicative factor), which is expressed as.

$k=\frac{\int_{\mathrm{R}} S_{\text {in }} h d \Omega}{\int_{\mathrm{R}} S_{\text {in }} \hat{h} d \Omega}$ 
Fig. 7 a TWS variations from the GLDAS Noah model in

March 2003. b The grid in panel (a) is transformed to the spherical harmonic domain and up to $\mathrm{d} / \mathrm{o}$ 60. c Leakage-out and d leakagein effects because of the limited spherical harmonic expansion. The white lines show the boundaries of the Amazon River basin

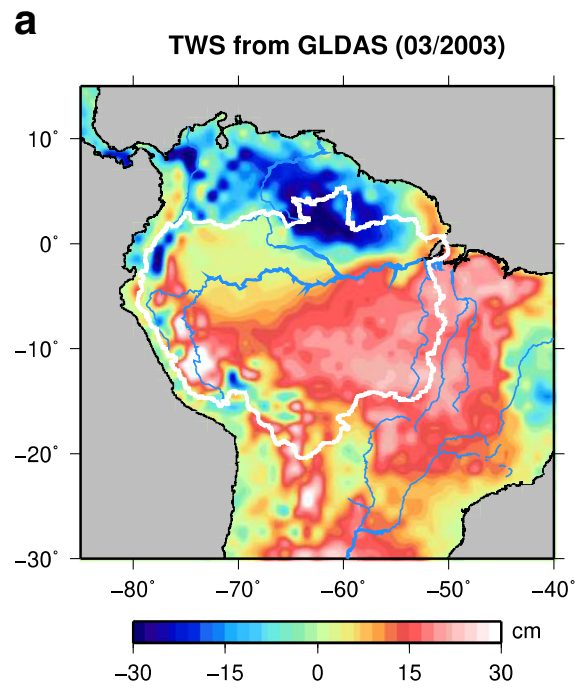

b

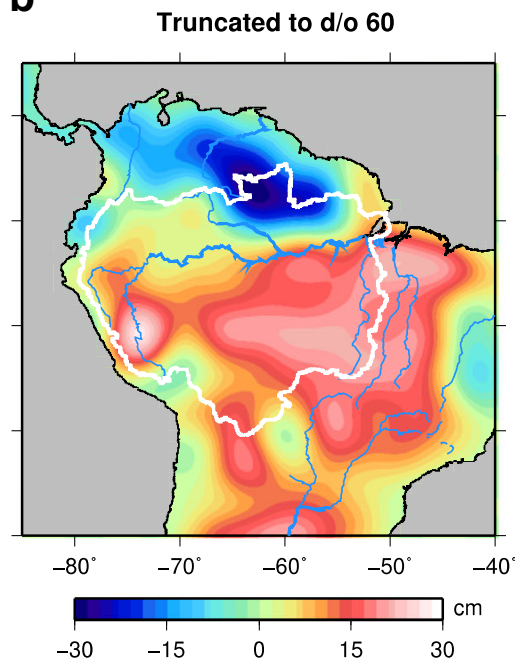

C

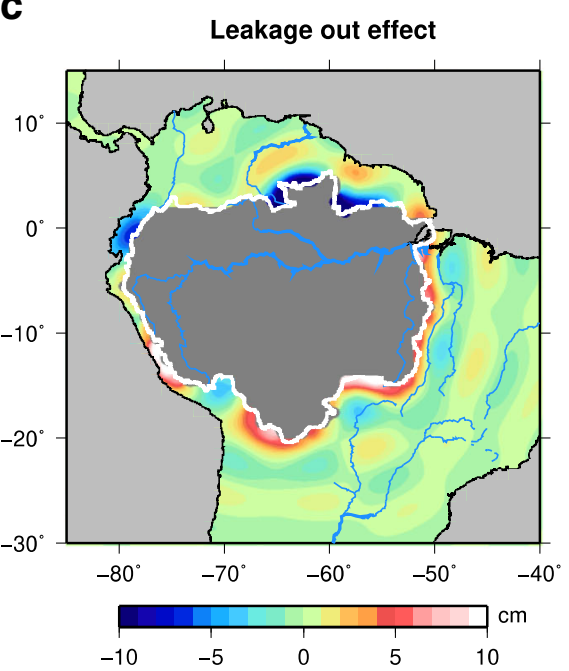

d

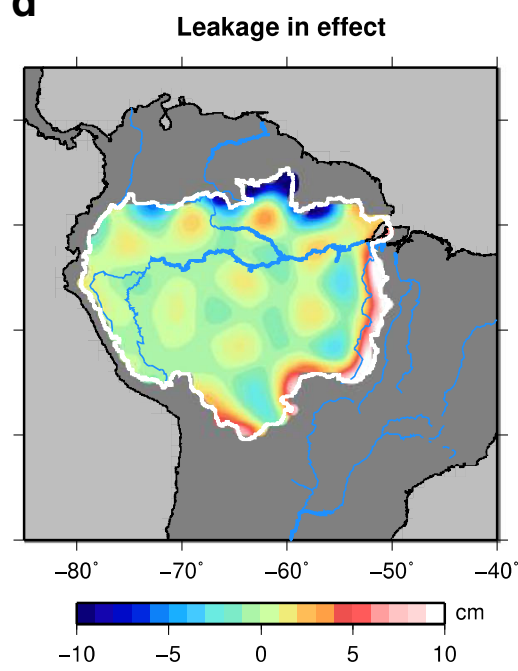

If reliable mass variations over the study region are available, we can use this equation to estimate the scaling factor, but this availability is not guaranteed. Assuming a uniform mass variation in the region of interest, $k$ is simplified to.

$k=\frac{R_{0}}{\int_{\mathrm{R}} \hat{h} d \Omega}$

Next, to estimate the scaling factor, we need to construct an ideal kernel for the region of interest (1 inside and 0 outside), and decompose it into a limited set of SH coefficients based on the function gmt_grid2cs, then apply the destriping and smoothing process to the corresponding set of SH coefficients based on the functions of $\mathrm{gmt}$ destriping and gmt_gaussian_filter. After that, the SH coefficients need to be converted to gridded values in the spatial domain using gmt cs2grid. Finally, the remaining signal in the region is derived based on the function gmt grid2series. The reciprocal of the remaining signal is considered the scaling factor. For example, Fig. 8a shows the ideal kernel for the Amazon River basin ( 1 inside and 0 outside). After the SH expansion of the ideal kernel to d/o 60 and a $300 \mathrm{~km}$ Gaussian smoothing applied, the remaining mean signal in the basin is approximately 0.85 (Fig. 8b). Hence, to derive an unbiased estimate in the basin, a scaling factor of 1.18 should be applied to the averaging kernel. Figure $8 \mathrm{c}$ also shows the rescaled averaging kernel in the spatial domain.

The scaling method has been extensively used to derive the unbiased mass variation time series for the region of interest. For example, to calibrate the GRACE estimate in the study of mass balance in Antarctica, Velicogna and Wahr (2006b) applied the averaging function to a uniform mass variation over the ice sheet, and the remaining signal in the region was 0.62 . Thus, they applied the GRACE estimate with a scaling factor of $1 / 0.62$ to recover the actual mass variation signal over the entire ice sheet. In the Caspian Sea, a scaling factor of $1 / 0.37$ is multiplied with the GRACE original estimate to analyze the water storage variations (Swenson and Wahr 2007). A scaling 
Fig. 8 a Ideal basin kernel for the Amazon River basin (i.e., ones in the basin and zeroes outside). $\mathbf{b}$ Averaging kernel derived by the $\mathrm{SH}$ expansion of the ideal kernel to d/o 60 with a $300 \mathrm{~km}$ Gaussian smoothing. c Rescaled averaging kernel derived by multiplying the averaging kernel in panel (b) with a scaling factor of 1.18
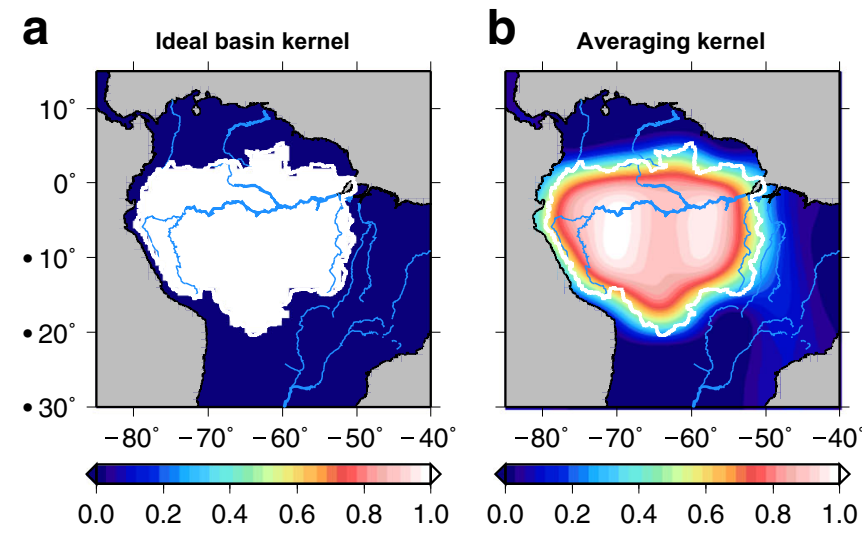

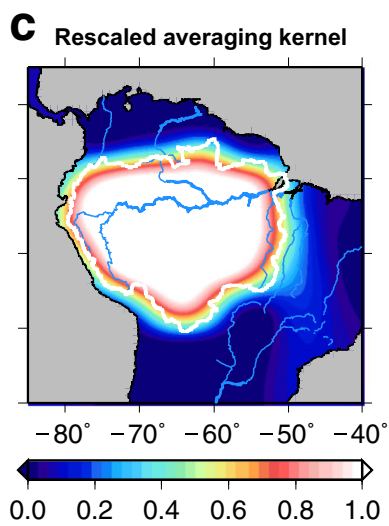

factor of 1.95 is determined to recover the magnitude damping of GRACE-based groundwater storage variations in northern India (Rodell et al. 2009). For more details on leakage reduction and rescaling, we refer readers to the reviews by Longuevergne et al. (2010), Feng (2014), and Long et al. (2015).

\section{Assessment of GRACE measurement error}

In addition to estimating unbiased mass variation series in a target region, the GRAMAT can be used to assess the GRACE measurement error, which can be estimated by two methods generally. In the first method, the measurement error in a given region can be estimated as a root-mean-square (RMS) variability over the oceans at the same latitude as the study region on land (Chen et al. 2009b). If the ocean and atmosphere models perfectly simulate the mass change over the oceans, after the de-aliasing processing, no mass change is detected by GRACE. Therefore, the residuals over the ocean can approximately represent the GRACE measurement error. Note that the ocean variability and deficiencies in the de-aliasing products are included in estimates of the GRACE error. Thus, this approach may overestimate the GRACE measurement error. In contrast to the aforementioned uncertainty estimation in the spatial domain, Wahr et al. (2006) used the second method to determine the uncertainties in the GRACE SH coefficients as the standard deviation of the residuals of coefficients when seasonal cycles were removed. This method may also overestimate the GRACE measurement error because we assume that all non-seasonal variability of Stokes coefficients results from the measurement error. The function gmt_cs_error can be used to estimate the uncertainties in the GRACE SH coefficients; then, the function gmt_cs2grid can be used to further estimate the uncertainties in the spatial domain.

As an example, Fig. 9 shows the spatial patterns of GRACE measurement errors in November 2003 obtained from the original SH coefficients and filtered SH coefficients with a $300 \mathrm{~km}$ Gaussian smoothing based on the gmt_cs_error and gmt cs2grid functions in GRAMAT. As shown in Fig. 9, the GRACE measurement errors depend on the latitude and show high uncertainties in the tropics and low uncertainties in the polar regions, which is consistent with the results of Wahr et al. (2006). Lower uncertainties in the polar regions are primarily due to more observations in these regions because of the near-polar orbit of GRACE satellites. In Fig. 9b, when a $300 \mathrm{~km}$ Gaussian smoothing is applied, the magnitude of the GRACE measurement error decreases significantly.

Note that the total uncertainty of GRACE estimates is the sum of different error components in quadrature, which includes not only the GRACE measurement error, but also the uncertainty of the leakage correction, and the uncertainty of the scaling factor (e.g., Longuevergne et al. 2010). The uncertainty of the leakage correction can be estimated as the standard deviation of leakage corrections from different hydrological models. The uncertainty of the scaling factor can also be assessed by comparing the scaling factor estimate based on the uniform assumption in the study region and those based on different mass distributions from hydrological models or
Fig. 9 Spatial patterns of GRACE measurement errors in November 2003 (a) without Gaussian smoothing and (b) with a $300 \mathrm{~km}$ Gaussian smoothing
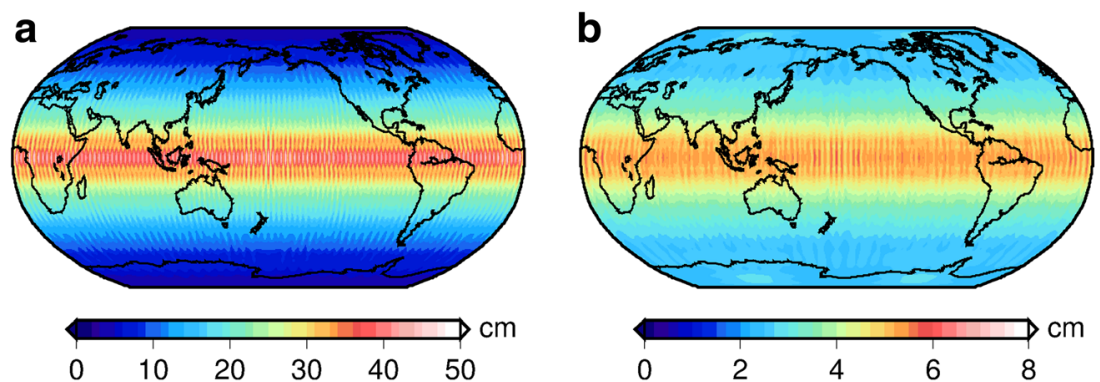

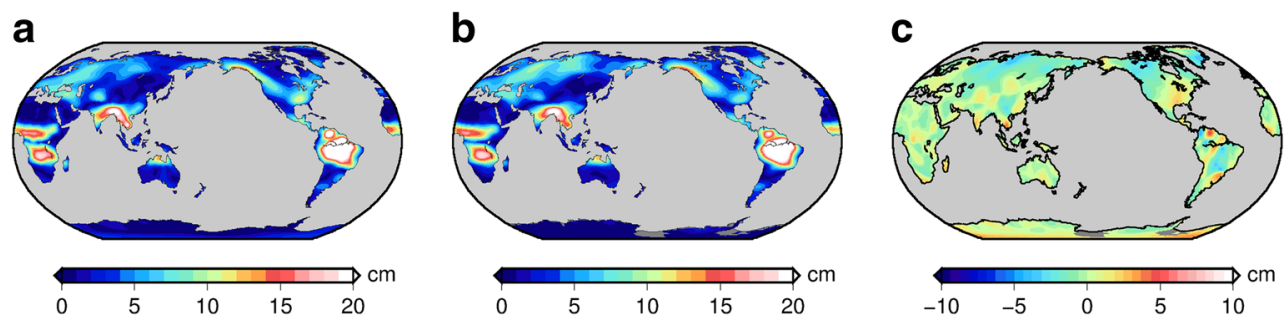

Fig. 10 Annual amplitudes of GRACE-derived TWS based on Swenson destriping and a $300 \mathrm{~km}$ Gaussian filter. (a) and (b) show the results based on the GRAMAT and official gridded level-3 products, respectively.

simulations (e.g., Rodell et al. 2009). The gridded mass changes from hydrological models are the input data for
Panel (c) shows the differences between the results from GRAMAT and official products. Note that different color bar is used for the panel (c)

GRAMAT, so the uncertainties in these models are not considered in the current version of GRAMAT.
Fig. 11 a Time series of the GRACE-derived TWS variations in the Amazon River basin (red dots). The error bars represent the uncertainties of TWS estimates (one-sigma standard deviations). The blue line represents the seasonal and long-term changes of TWS, which were computed based on the gmt harmonic function of the GRAMAT. b Interannual TWS variations (red dotted line) and precipitation anomalies (blue bars) in the Amazon River basin. Seasonal cycles and the linear trend were removed, and a three-month moving average was applied. The precipitation anomalies were shifted by two months

considering the delayed response of TWS to precipitation a

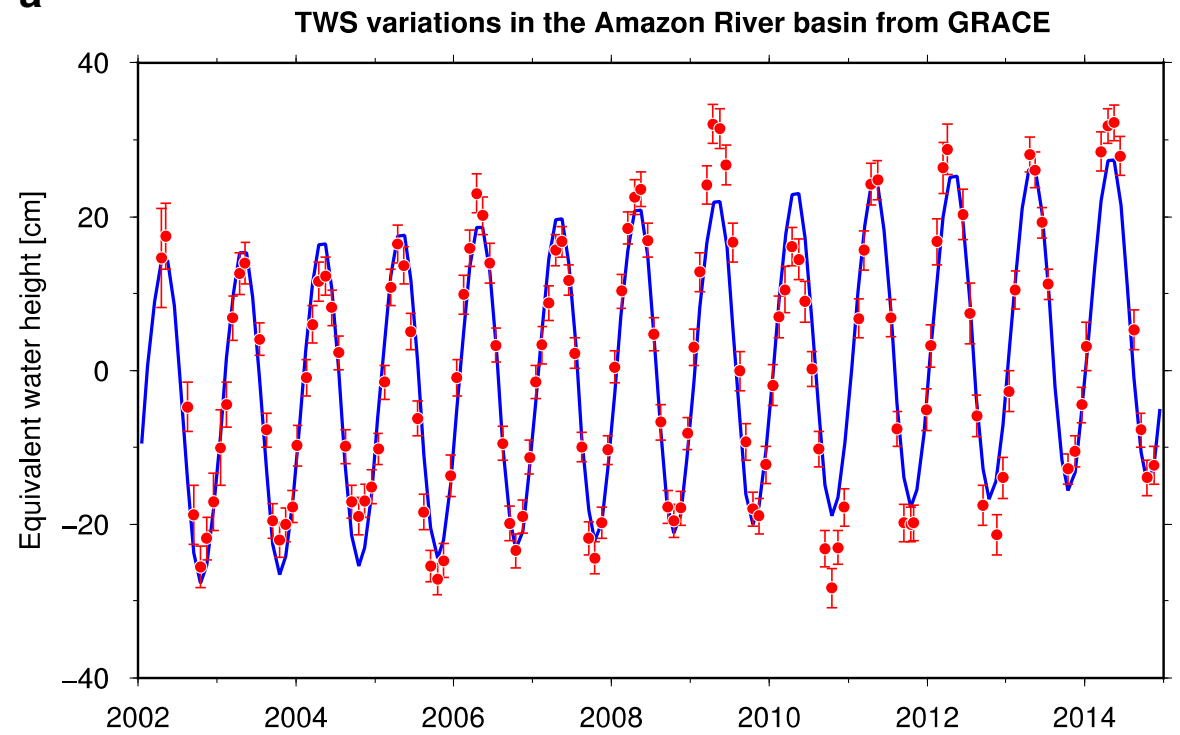

b

Interannual TWS variations and precipitation anomalies in the Amazon River basin

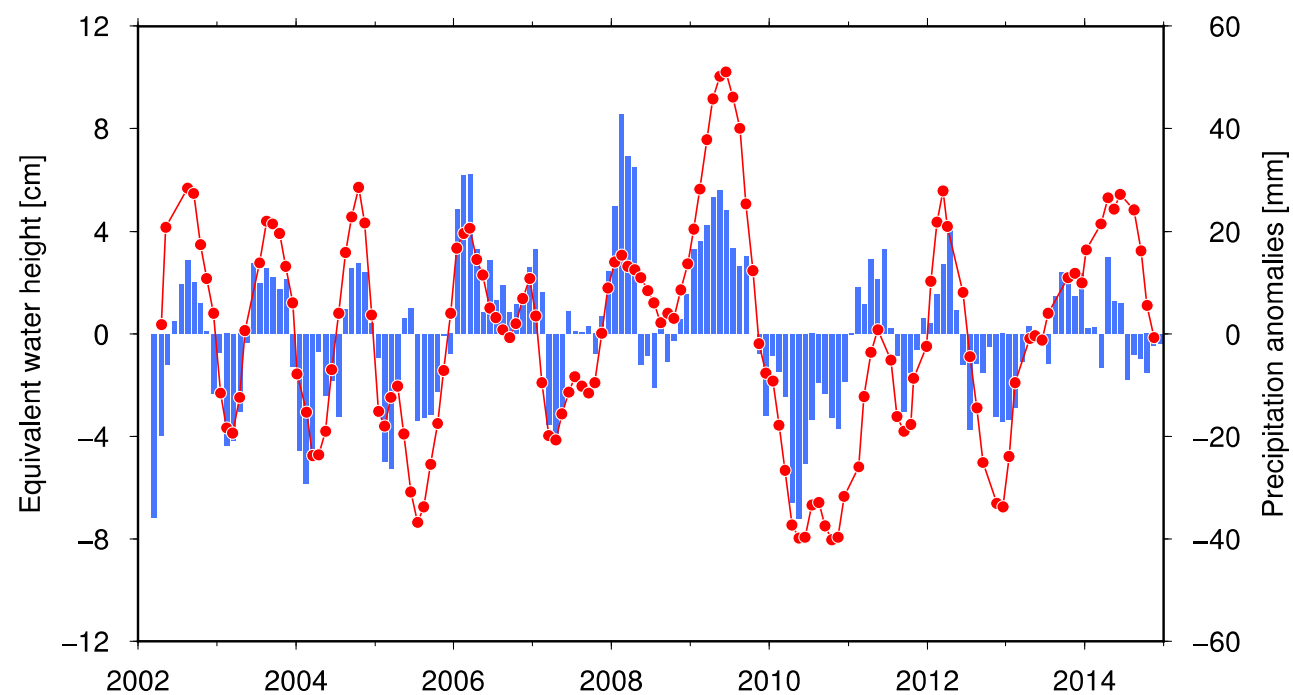


Fig. 12 Spatial patterns of the annual amplitudes (a) and phases (b) of TWS variations over the Amazon River basin

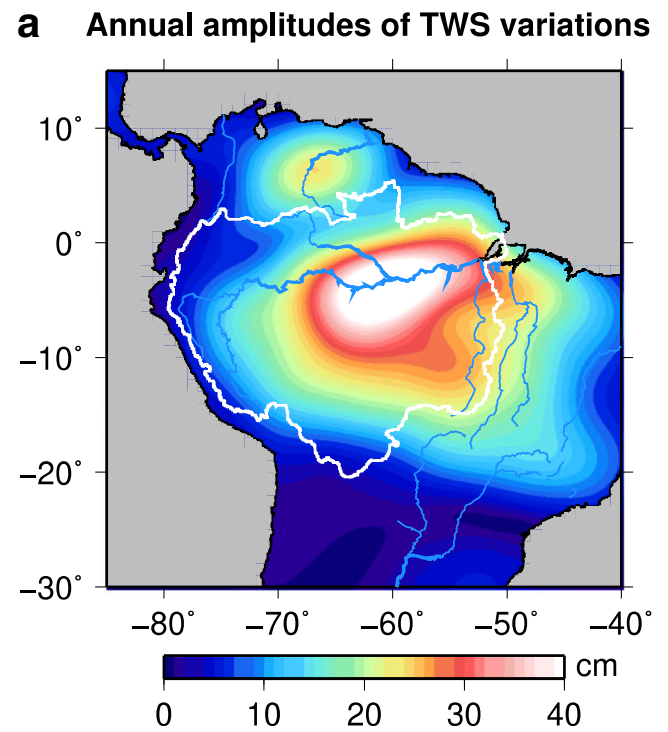

b Annual phases of TWS variations

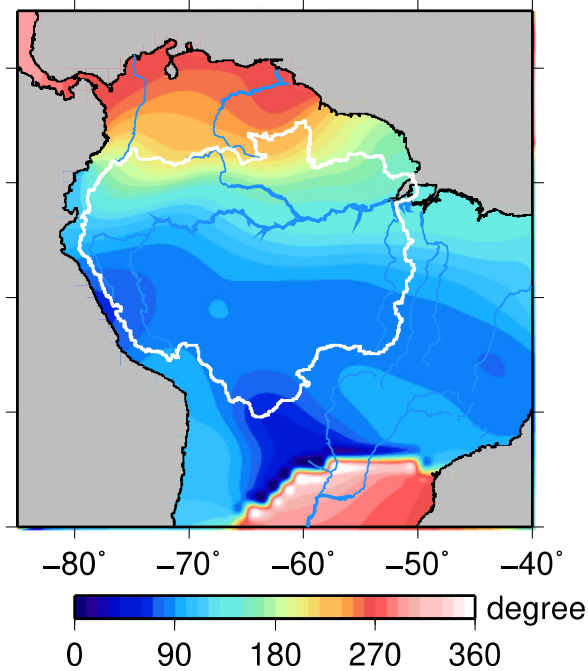

\section{GRAMAT application: A case study in the Amazon River basin}

As a case study, we calculated the TWS variations in the Amazon River basin, the site of the world's largest annual TWS variations (Fig. 10). We run the script file GRACE_Matlab_Toolbox_preprocessing_core.m with the control file as shown in Fig. 3. Monthly GRACE Release-05 level-2 GSM products from CSR were used to estimate the TWS variations. GRACE GSM products mainly represent the hydrological and geophysical signals on the land, because the mass variations in the atmosphere and ocean have been removed. To reduce the correlated north-south stripes and shortwavelength noise in the original GRACE GSM products, the Swenson destriping method and a $300 \mathrm{~km}$ Gauss smoothing filter were applied (Swenson and Wahr 2006; Wahr et al. 1998). In addition, first-degree terms and $\mathrm{C}_{20}$ terms of the $\mathrm{SH}$ coefficients were replaced by estimates from satellite laser ranging observations and ocean and atmosphere models (Cheng et al. 2011; Swenson et al. 2008). The GRACE data were further corrected for Glacial Isostatic Adjustment (GIA) on the basis of the model from A et al. (2013). The leakage effect was estimated from the average of four GLDAS models (Noah, VIC, Mosaic, and CLM) (Ek et al. 2003; Koster and Suarez 1992; Liang et al. 1994; Rodell et al. 2004) and removed from the GRACE TWS variation time series. After the leakage reduction process, the rescaled averaging kernel shown in Fig. 8c was applied to retrieve TWS variations in the Amazon River basin. The uncertainty of the GRACE-derived TWS variation estimates was computed as the square root of the sum of different error components' squares. These error components contain the GRACE measurement error estimated based on the method proposed by Wahr et al. (2006) and the errors caused during the leakage reduction and rescaling (Longuevergne et al. 2010).

As shown in Fig. 10a, b, the global spatial pattern of TWS annual amplitudes is consistent with the result based on
Fig. 13 Spatial patterns of TWS anomalies in April 2009 (a) and September 2010 (b). The seasonal cycles have been removed based on the gmt harmonic function in GRAMAT

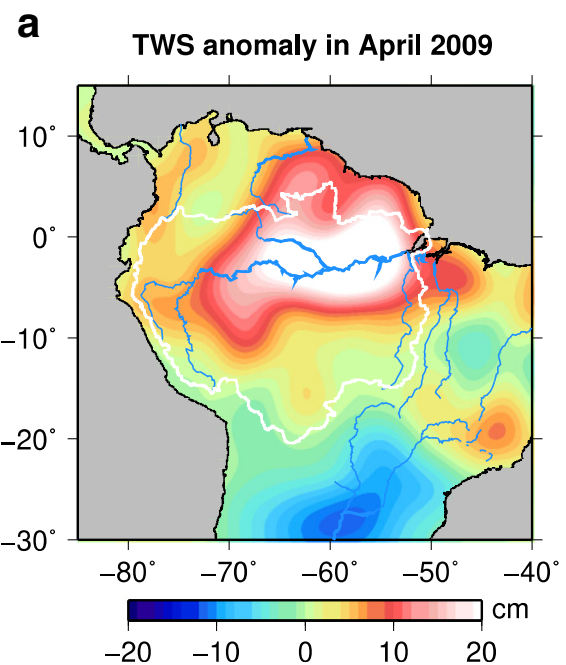

b

TWS anomaly in September 2010

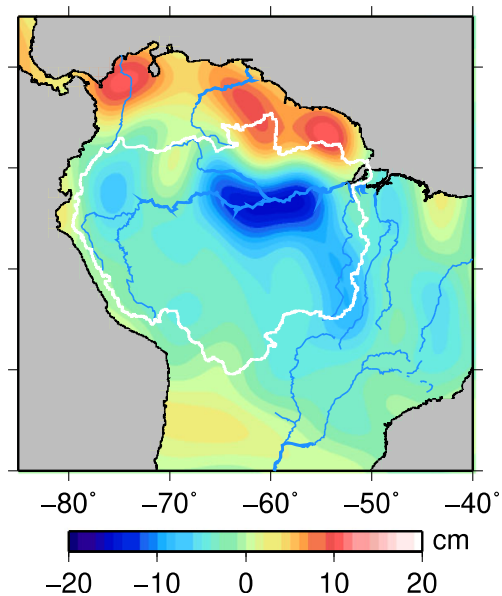


official GRACE level-3 gridded products, which confirms the effectivity of the GRAMAT. The differences between them are relatively small and in the similar magnitude as the nominal GRACE accuracy, i.e., $\sim 2 \mathrm{~cm}$ at the spatial resolution of $300 \mathrm{~km}$ (Wahr et al. 2006). The GRACE-derived TWS shows significant seasonal variations in the Amazon River basin, with an annual amplitude of $21.5 \pm 1.1 \mathrm{~cm}$, and reaches a maximum in April (Fig. 11a). The largest annual variation occurs along the main stream of the river (Fig. 12a). In the spatial domain, the maximum annual phases of TWS variations change gradually from March in the southern Amazon to August in the northern Amazon (Fig. 12b). In addition, by comparing the original TWS time series and modeled linear and seasonal changes, we find significantly abnormal TWS increase in 2009 and TWS loss in 2010 (Fig. 11a). Based on the function gmt_harmonic, we removed seasonal cycles and the linear trend from the original time series and applied a three-month moving average to derive the interannual TWS variations in the Amazon River basin and compared them with precipitation anomalies from the Global Precipitation Climatology Centre (GPCC) monthly dataset (Schneider et al. 2014). Note that the GPCC precipitation data reading and processing are not included in GRAMAT. As shown in Fig. $11 \mathrm{~b}$, the precipitation anomalies correlated well with GRACE-derived interannual TWS variations. On interannual timescales, the positive precipitation anomalies coincide with the TWS increase; and vice versa. For example, the increase in precipitation in 2009 is consistent with the GRACE-derived TWS surplus. The severe drought event in 2010 with significant precipitation deficiency is also consistent with the TWS loss detected by GRACE. Furthermore, we calculated the spatial patterns of the TWS anomaly in April 2009 and September 2010 after removing the seasonal cycles based on the gmt_harmonic function in GRAMAT. As shown in Fig. 13, both the abnormal TWS increase and loss detected by GRACE occurred along the main stream of the Amazon River, which indicates the main contribution of surface water to the total TWS variations in the basin.

\section{Concluding remarks}

In this paper, we present a GRACE Matlab Toolbox (GRAMAT) to process GRACE level-2 data and estimate spatio-temporal mass variations. This open-source package is likely to be useful for the Earth science community, especially for hydrologists, who are prone to ignore the non-negligible signal distortion and errors during the GRACE level-2 data processing and use GRACE level-3 gridded products directly. Note that the leakage and bias effects and the rescaling can be assessed in this toolbox, which will be very helpful for analyzing the uncertainties in GRACE when comparing GRACE results with other independent observations or model outputs. The GRAMAT provides widely used destriping methods to remove "north-to-south" stripes in the GRACE original Stokes coefficients and retrieve unbiased regional mass variation time series. In addition, harmonic analysis is provided in the package to estimate seasonal cycles, the longterm trend and interannual variations of time series. A case study on TWS variations in the Amazon River basin based on the GRACE data and the GRAMAT further indicate the potentially wide application of the toolbox developed in this study.

Acknowledgments This work is supported by the National Natural Science Foundation of China (Grant Nos. 41431070, 41674084, 41874095 and 41621091). We acknowledge F. Simons for making his codes on spherical harmonic analysis and synthesis available (http:// geoweb.princeton.edu/people/simons/software.html). The GRACE data used in this study can be download at http://podaac.jpl.nasa.gov/GRACE. Part of this work was initiated during the stay of the author at CNES/GRGS, thanks to the Sino-French Joint Ph.D. Scholarship Program.

Availability and requirements The GRAMAT can be downloaded from the website https://github.com/fengweiigg/GRACE_Matlab_Toolbox. All the files required for the installation and use of the toolbox are freely distributed through this public Git repository. The toolbox was developed on the MacOSX operating systems with the Matlab software (version R2014a) from the MathWorks, Inc.

Open Access This article is distributed under the terms of the Creative Commons Attribution 4.0 International License (http:// creativecommons.org/licenses/by/4.0/), which permits unrestricted use, distribution, and reproduction in any medium, provided you give appropriate credit to the original author(s) and the source, provide a link to the Creative Commons license, and indicate if changes were made.

Publisher's note Springer Nature remains neutral with regard to jurisdictional claims in published maps and institutional affiliations.

\section{References}

A G, Wahr J, Zhong S (2013) Computations of the viscoelastic response of a 3-D compressible earth to surface loading: an application to glacial isostatic adjustment in Antarctica and Canada. Geophys J Int 192:557-572. https://doi.org/10.1093/gji/ggs030

Boening C, Willis JK, Landerer FW, Nerem RS, Fasullo J (2012) The 2011 La Niña: So strong, the oceans fell. Geophys Res Lett 39: L19602. https://doi.org/10.11029/12012GL053055

Cazenave A, Dominh K, Guinehut S, Berthier E, Llovel W, Ramillien G, Ablain M, Larnicol G (2009) Sea level budget over 2003-2008: a reevaluation from GRACE space gravimetry, satellite altimetry and Argo. Glob Planet Chang 65:83-88. https://doi.org/10.1016/j. gloplacha.2008.10.004

Chambers DP (2006) Evaluation of new GRACE time-variable gravity data over the ocean. Geophys Res Lett 33:L17603. https://doi.org/ 10.1029/2006GL027296

Chambers D, Bonin J (2012) Evaluation of Release-05 GRACE time-variable gravity coefficients over the ocean. Ocean Sci Discuss 9:2187-2214

Chen JL, Wilson CR, Tapley BD, Blankenship DD, Ivins ER (2007a) Patagonia icefield melting observed by gravity recovery and climate experiment (GRACE). Geophys Res Lett 34:L22501. https://doi. org/10.1029/2007g1031871

Chen JL, Wilson CR, Tapley BD, Grand S (2007b) GRACE detects coseismic and postseismic deformation from the Sumatra- 
Andaman earthquake. Geophys Res Lett 34:L13302. https://doi.org/ 10.1029/2007g1030356

Chen JL, Wilson CR, Tapley BD, Blankenship D, Young D (2008) Antarctic regional ice loss rates from GRACE. Earth Planet Sci Lett 266:140-148. https://doi.org/10.1016/j.epsl.2007.10.057

Chen JL, Wilson CR, Blankenship D, Tapley BD (2009a) Accelerated Antarctic ice loss from satellite gravity measurements. Nat Geosci 2: 859-862

Chen JL, Wilson CR, Tapley BD, Yang ZL, Niu GY (2009b) 2005 drought event in the Amazon River basin as measured by GRACE and estimated by climate models. J Geophys Res 114:B05404. https://doi.org/10.1029/2008jb006056

Chen JL, Wilson CR, Tapley BD (2010a) The 2009 exceptional Amazon flood and interannual terrestrial water storage change observed by GRACE. Water Resour Res 46:W12526. https://doi.org/10.11029/ 12010WR009383

Chen JL, Wilson CR, Tapley BD, Longuevergne L, Yang ZL, Scanlon BR (2010b) Recent La Plata basin drought conditions observed by satellite gravimetry. J Geophys Res 115:D22108. https://doi.org/10. 1029/2010jd014689

Cheng M, Ries JC, Tapley BD (2011) Variations of the Earth's figure axis from satellite laser ranging and GRACE. J Geophys Res Atmospheres 116:B01409. https://doi.org/10.1029/2010jb000850

Cheng M, Tapley BD, Ries JC (2013) Deceleration in the Earth's oblateness. J Geophys Res 118:740-747. https://doi.org/10.1002/jgrb.50058

Davis JL, Tamisiea ME, Elosegui P, Mitrovica JX, Hill EM (2008) A statistical filtering approach for gravity recovery and climate experiment (GRACE) gravity data. J Geophys Res 113:B04410. https:// doi.org/10.1029/2007JB005043

Duan XJ, Guo JY, Shum CK, van der Wal W (2009) On the postprocessing removal of correlated errors in GRACE temporal gravity field solutions. J Geod 83:1095-1106. https://doi.org/10. 1007/S00190-009-0327-0

Ek M et al (2003) Implementation of Noah land surface model advances in the National Centers for environmental prediction operational mesoscale eta model. J Geophys Res 108:8851. https://doi.org/10. 1029/2002JD003296

Famiglietti J et al (2011) Satellites measure recent rates of groundwater depletion in California's Central Valley. Geophys Res Lett 38: L03403. https://doi.org/10.1029/2010GL046442

Feng W (2014) Regional terrestrial water storage and sea level variations inferred from satellite gravimetry. Universite Toulouse III Paul Sabatier

Feng W, Zhong M, Lemoine JM, Biancale R, Hsu HT, Xia J (2013) Evaluation of groundwater depletion in North China using the gravity recovery and climate experiment (GRACE) data and groundbased measurements. Water Resour Res 49:2110-2118. https://doi. org/10.1002/wrcr.20192

Feng W, Lemoine JM, Zhong M, Hsu HT (2014) Mass-Induced Sea level variations in the Red Sea from GRACE, steric-corrected altimetry, in situ bottom pressure records, and hydrographic observations. J Geodyn 78:1-7. https://doi.org/10.1016/j.jog.2014.04.008

Frappart F, Papa F, Da Silva JS, Ramillien G, Prigent C, Seyler F, Calmant S (2012) Surface freshwater storage and dynamics in the Amazon basin during the 2005 exceptional drought. Environ Res Lett 7. https://doi.org/10.1088/1748-9326/7/4/044010

García D, Chao B, Del Río J, Vigo I, García-Lafuente J (2006) On the steric and mass-induced contributions to the annual sea level variations in the Mediterranean Sea. J Geophys Res Oceans 111:C09030. https://doi.org/10.01029/02005JC002956

Han SC, Shum CK, Jekeli C, Kuo CY, Wilson C, Seo KW (2005) Nonisotropic filtering of GRACE temporal gravity for geophysical signal enhancement. Geophys J Int 163:18-25. https://doi.org/10.1111/ j.1365-246X.2005.02756.x

Han SC, Shum CK, Bevis M, Ji C, Kuo CY (2006) Crustal dilatation observed by GRACE after the 2004 Sumatra-Andaman earthquake. Science 313:658-662. https://doi.org/10.1126/science.1128661
Harig C, Simons FJ (2012) Mapping Greenland's mass loss in space and time. P Natl Acad Sci USA 109:19934-19937. https://doi.org/10. 1073/pnas.1206785109

Jacob T, Wahr J, Pfeffer WT, Swenson S (2012) Recent contributions of glaciers and ice caps to sea level rise. Nature 482:514-518. https:// doi.org/10.1038/nature10847

Jekeli C (1981) Alternative methods to smooth the Earth's gravity field, Rep. 327. Department of Geodetic Science and Surveying, The Ohio State University, Columbus

Joodaki G, Wahr J, Swenson S (2014) Estimating the human contribution to groundwater depletion in the Middle East, from GRACE data, land surface models, and well observations. Water Resour Res 50: 2679-2692. https://doi.org/10.1002/2013WR014633

King MA, Bingham RJ, Moore P, Whitehouse PL, Bentley MJ, Milne GA (2012) Lower satellite-gravimetry estimates of Antarctic Sealevel contribution. Nature 491:586-589

Klees R, Zapreeva EA, Winsemius HC, Savenije HHG (2007) The bias in GRACE estimates of continental water storage variations. Hydrol Earth Syst Sc 11:1227-1241

Koster RD, Suarez MJ (1992) Modeling the land surface boundary in climate models as a composite of independent vegetation stands. J Geophys Res 97:2697-2715. https://doi.org/10.1029/2691JD01696

Kusche J (2007) Approximate decorrelation and non-isotropic smoothing of time-variable GRACE-type gravity field models. J Geod 81:733749. https://doi.org/10.1007/s00190-007-0143-3

Kusche J, Uebbing B, Rietbroek R, Shum CK, Khan ZH (2016) Sea level budget in the bay of Bengal (2002-2014) from GRACE and altimetry. J Geophys Res Oceans 121:1194-1217. https://doi.org/10. 1002/2015JC011471

Liang X, Lettenmaier DP, Wood EF, Burges SJ (1994) A simple hydrologically based model of land surface water and energy fluxes for general circulation models. J Geophys Res 99:14415-14428

Long D, Longuevergne L, Scanlon BR (2015) Global analysis of approaches for deriving total water storage changes from GRACE satellites. Water Resour Res 51:2574-2594. https://doi.org/10. 1002/2014WR016853

Long D, Chen X, Scanlon BR, Wada Y, Hong Y, Singh VP, Chen Y, Wang C, Han Z, Yang W (2016) Have GRACE satellites overestimated groundwater depletion in the Northwest India aquifer? Sci Rep 6:24398. https://doi.org/10.1038/srep24398

Longuevergne L, Scanlon BR, Wilson CR (2010) GRACE hydrological estimates for small basins: evaluating processing approaches on the High Plains aquifer, USA. Water Resour Res 46:W11517. https:// doi.org/10.1029/2009WR008564

Matsuo K, Heki K (2010) Time-variable ice loss in Asian high mountains from satellite gravimetry. Earth Planet Sci Lett 290:30-36

Panet I, Mikhailov V, Diament M, Pollitz F, King G, de Viron O, Holschneider M, Biancale R, Lemoine JM (2007) Coseismic and post-seismic signatures of the Sumatra 2004 December and 2005 march earthquakes in GRACE satellite gravity. Geophys J Int 171: 177-190. https://doi.org/10.1111/j.1365-246X.2007.03525.x

Rodell M, Houser PR, Jambor U, Gottschalck J, Mitchell K, Meng CJ, Arsenault K, Cosgrove B, Radakovich J, Bosilovich M, Entin JK, Walker JP, Lohmann D, Toll D (2004) The global land data assimilation system. Bull Amer Meteor Soc 85:381-394. https://doi.org/ 10.1175/bams-85-3-381

Rodell M, Velicogna I, Famiglietti JS (2009) Satellite-based estimates of groundwater depletion in India. Nature 460:999-1002. https://doi. org/10.1038/nature08238

Sasgen I, Martinec Z, Fleming K (2007) Wiener optimal combination and evaluation of the gravity recovery and climate experiment (GRACE) gravity fields over Antarctica. J Geophys Res 112:B04401. https:// doi.org/10.1029/2006JB004605

Scanlon BR, Longuevergne L, Long D (2012) Ground referencing GRACE satellite estimates of groundwater storage changes in the 
California Central Valley, USA. Water Resour Res 48:W04520. https://doi.org/10.1029/2011WR011312

Schmidt M, Han SC, Kusche J, Sanchez L, Shum CK (2006) Regional high-resolution spatiotemporal gravity modeling from GRACE data using spherical wavelets. Geophys Res Lett 33:L08403. https://doi. org/10.1029/2005GL025509

Schneider U, Becker A, Finger P, Meyer-Christoffer A, Ziese M, Rudolf B (2014) GPCC's new land surface precipitation climatology based on quality-controlled in situ data and its role in quantifying the global water cycle. Theor Appl Climatol 115:15-40. https://doi. org/10.1007/s00704-013-0860-x

Schrama EJO, Wouters B, Rietbroek R (2014) A mascon approach to assess ice sheet and glacier mass balances and their uncertainties from GRACE data. J Geophys Res 119:6048-6066. https://doi. org/10.1002/2013JB010923

Swenson S, Wahr J (2002) Methods for inferring regional surface-mass anomalies from gravity recovery and climate experiment (GRACE) measurements of time-variable gravity. J Geophys Res 107(2193): ETG 3-1-ETG 3-13. https://doi.org/10.1029/2001jb000576

Swenson S, Wahr J (2006) Post-processing removal of correlated errors in GRACE data. Geophys Res Lett 33:L08402. https://doi.org/10. 1029/2005GL025285

Swenson S, Wahr J (2007) Multi-sensor analysis of water storage variations of the Caspian Sea. Geophys Res Lett 34:L16401. https://doi. org/10.1029/2007GL030733

Swenson S, Chambers D, Wahr J (2008) Estimating geocenter variations from a combination of GRACE and ocean model output. J Geophys Res 113:B08410. https://doi.org/10.1029/2007jb005338
Tapley BD, Bettadpur S, Ries JC, Thompson PF, Watkins MM (2004) GRACE measurements of mass variability in the earth system. Science 305:503-505. https://doi.org/10.1126/science.1099192

Tiwari VM, Wahr J, Swenson S (2009) Dwindling groundwater resources in northern India, from satellite gravity observations. Geophys Res Lett 36:L18401. https://doi.org/10.1029/2009GL039401

Velicogna I, Wahr J (2006a) Acceleration of Greenland ice mass loss in spring 2004. Nature 443:329-331. https://doi.org/10.1038/ nature 05168

Velicogna I, Wahr J (2006b) Measurements of time-variable gravity show mass loss in Antarctica. Science 311:1754-1756. https://doi.org/10. 1126/science. 1123785

Wahr J, Molenaar M, Bryan F (1998) Time variability of the Earth's gravity field: hydrological and oceanic effects and their possible detection using GRACE. J Geophys Res 103:30205-30229

Wahr J, Swenson S, Velicogna I (2006) Accuracy of GRACE mass estimates. Geophys Res Lett 33:L06401. https://doi.org/10.1029/ $2005 \mathrm{~g} 1025305$

Willis JK, Chambers DP, Nerem RS (2008) Assessing the globally averaged sea level budget on seasonal to interannual timescales. J Geophys Res Oceans 113:C06015. https://doi.org/10.1029/ 2007JC004517

Yi S, Sun W (2014) Evaluation of glacier changes in high-mountain Asia based on 10 year GRACE RL05 models. J Geophys Res 119:2504 2517. https://doi.org/10.1002/2013JB010860

Zhang ZZ, Chao BF, Lu Y, Hsu HT (2009) An effective filtering for GRACE time-variable gravity: fan filter. Geophys Res Lett 36: L17311. https://doi.org/10.1029/2009GL039459 